York W. Bradshaw, Johannes Britz, Theo Bothma and Coetzee Bester

\title{
Using Information Technology to Create Global Classrooms: Benefits and Ethical Dilemmas
}

\begin{abstract}
:
The global digital divide represents one of the most significant examples of international inequality. In North America and Western Europe, nearly $70 \%$ of citizens use the Internet on a regular basis, whereas in Africa less than $4 \%$ do so. Such inequality impacts business and trade, online education and libraries, telemedicine and health resources, and political information and e-government. In response, a group of educators and community leaders in South Africa and the United States have used various information technologies to create a "global classroom" that connects people in the two countries. University students, high school students, and other citizens communicate via Internet exchanges, video conferencing, and digital photo essays. The project has produced a number of tangible benefits and it has developed a model for reducing inequality in global education, at least for those institutions with the technological resources to participate. We also present several recommendations for how to expand the initiative and thereby increase the number of people who can benefit from it.
\end{abstract}

\section{Agenda}

Introduction

Theoretical Issues....

Background .333

Early Lessons Learned

First Global Classroom: University of Pretoria and University of Memphis

Broadening the Scope: Subsequent Global Classrooms

Conclusion and Recommendations

\section{Authors:}

York W. Bradshaw:

- University of South Carolina Upstate

Johannes Britz

- University of Wisconsin Milwaukee, USA, University of Pretoria, SA

- Department of Information Science, University of Pretoria, Lynnwood road, Pretoria, South Africa

Theo Bothma

- University of Pretoria

Coetzee Bester

- Africa Institute for Leadership, Research \& Development 


\section{Introduction}

Global inequality is an enduring reality, and no where is this more evident than when examining the global digital divide. Across Africa, for example, only 3.6 percent of the population uses the Internet, well below the world average of 16.9 percent. At the upper end of the world system, twenty-four countries (primarily in North America and Europe) have Internet usage rates that exceed 60 percent and five are higher than 70 percent (Internet World Stats, 2007). This global digital divide impacts business and trade, online education and libraries, telemedicine and health resources, and political information and e-government.

Inequalities in information technology clearly represent an ethical issue (see Britz, 2007). The "wired" world has distinct advantages over the "unwired" world in terms of access to resources and opportunities. These advantages perpetuate global inequality and make it more difficult for the developing world to catch up. As discussed below, solutions to the global digital divide are extremely difficult to implement for a variety of reasons.

This paper discusses an on-going project that uses information technology to facilitate greater equality in global education. More specifically, for more than five years, a group of university professors, secondary school teachers, government leaders, and NGO leaders in South Africa and the United States have formed a unique "global classroom" that facilitates international education and inter-cultural understanding. We discuss this project in substantial detail and then examine its implications for ethical issues related to development, equality, and social justice.

\section{Theoretical Issues}

There is no question that information technology has altered the world economy in many ways (see Sassen, 2006). International capital flows, global trade, and the exchange of electronic information have changed the way that companies and individuals conduct business. Distance and place are less and less important as information technologies facilitate connections between people and companies, regardless of their geographic location. The problem, of course, is that not everyone has access to these technology resources. Lack of access to computers, the Internet, and other forms of elec- tronic information makes it virtually impossible for some countries - and their citizens - to participate fully in the global economy (Britz, Lor, and Bothma, 2006). Moreover, because information technology is associated with better health and overall quality of life, the many countries with low levels of information technology are at a distinct disadvantage relative to economically developed nations (Bradshaw, Fallon and Viterna, 2005).

A number of scholars argue that information poverty is an ethical issue - a moral issue - precisely because it is correlated with other types of poverty (Capurro, 2000; Britz, 2004; Britz and Blignaut, 2001). Remedying the global digital divide is, according to this perspective, a matter of social justice. Information technology is part of the "formula" for developing poor regions, a process that is hampered by the fact that rich and powerful countries control the global information system. Interestingly, this view is consistent with both the "cyberoptimist" and "cyber-pessimist" theories outlined by Pippa Norris in her book, Digital divide: civic engagement, information poverty, and the internet worldwide (2001). On the one hand, cyberoptimists assert that information technology is a positive force in the world today. It is associated with economic growth, health, democracy, and other features that typically characterize societal development. On the other hand, although cyberpessimists do not disagree with these sentiments, they assert that rich countries maintain control over information technology and insure its unequal distribution globally. Thus, rich countries utilize information technology for their own benefit, at the expense of poor countries.

Below, we discuss an innovative project that has the capacity to create greater equality of access to educational resources through the use of information technology.

\section{Background}

In October of 2002, Johannes Britz attended an "Ethics of Electronic Information Conference" at the University of Memphis in the USA. At the time, Prof. Britz was a Professor in the Department of Information Science at the University of Pretoria. One of his major research and teaching interests focused on information poverty as an issue of social justice. During the conference, Prof. Britz met York Bradshaw, who was the Chair of the Department of Sociology at the University of Memphis. One of Prof. Bradshaw's research and teaching interests 
examined the impact of information technology on development and quality of life in poor countries.

Over the next few months, Profs. Britz and Bradshaw continued a dialogue that ultimately expressed a desire to initiate the following:

- Connect classes at the University of Pretoria and the University of Memphis through the use of information technology.

- In the classes, examine the effects of information technology on various social, political, and cultural issues. One important question is whether inequalities in access to information technology are correlated with inequalities in development.

- Examine all of these inequalities within an ethical context. For example, "information poverty" represents an ethical challenge because it translates into a poorer quality of life in the developing world.

During January - March of 2003, Profs. Britz and Bradshaw began talking with their colleagues about these issues. Prof. Britz enlisted the collaboration of Prof. Theo Botma (Chair of Information Science at the University of Pretoria) and Mr. Coetzee Bester (Executive Director of the Africa Institute of Leadership, Research \& Development - and a former Member of the South African Parliament). And Prof. Bradshaw enlisted the collaboration of Dr. Wanda Rushing, an Associate Professor of Sociology at the University of Memphis. The larger group began to work together to outline a curriculum for a course that would accomplish the objectives noted earlier.

The group decided to launch its first "global classroom" during September of 2003. During May August, the following was accomplished:

- Two courses were identified as ideal for the new initiative. One course was "Information and Development" at the University of Pretoria (taught by Prof. Britz and Mr. Coetzee Bester) and the other was "Globalization, Culture, and Information Technology: Is 'Place' Still Relevant?" (taught by Profs. Bradshaw and Rushing).

- Profs. Bradshaw and Rushing traveled to Pretoria to work with their South African colleagues on the course content and objectives. The group decided that the two classes would share about $60 \%$ of the overall course content. In other words, both sides would collaborate on $60 \%$ of the "global classroom" course and keep $40 \%$ of their courses separate. This was necessary because the academic calendars are different in Pretoria and Memphis. The Pretoria courses begin and end nearly a month before the Memphis courses.

- Pretoria students enrolled in the "Informational and Development" course and paid local fees to the University of Pretoria, and Memphis students enrolled in the "Globalization" course and paid local fees to the University of Memphis.

- The faculty members worked out common readings (for the $60 \%$ of the course that would be shared), course assignments, and assessment guides. The group also decided on a web design for the course, which was hosted at the University of Memphis. All students who were enrolled in the global classroom course (from both Pretoria and Memphis) were given full access to the course web site. Because WebCT was widely used on both campuses, it was selected as the course platform.

After ten months of dialogue and about six months of intensive planning and curriculum development, the Universities of Pretoria and Memphis were prepared to launch their first truly global classroom initiative.

\section{Early Lessons Learned}

Even before the course officially commenced, we had already learned several valuable lessons that have endured through the years. We consider these issues a "must" for a successful global classroom experience that relies heavily on information technology:

- Both sides should have at least one "champion" who will "sell" the course to colleagues and upper-level administrators, collaborate with others to work out details for the course (including all substantive, logistical, and technical issues), and trouble shoot when challenges occur (and they will occur!). Profs. Britz and Bradshaw served this role in the beginning.

- The "champions" must have the support of key administrators to accomplish course and program objectives. Administrators can provide crucial resources and support, and they can open doors (or close them!) when troubles emerge. Prof. Britz had the strong 
support of his department chair (Prof. Bothma), who enlisted the support of his dean. Prof. Bradshaw was the chair of his department and he enlisted the support of his dean. Great ideas, strong "champions," and excellent administrative support are "musts" when organizing global classroom experiences.

- Although champions are vital, a team effort is important especially as the project continues. Each side needs its own team and the respective teams need to work with each other to function as a "global team." The teams need not be large, but they do need to have clear objectives and work well together. We have already discussed how the teams worked together to plan the course and develop the curriculum.

- Part of the team effort includes strong support from the Information Technology Departments at both institutions. Equipment between institutions must be compatible and the "academic" part of the course must be coordinated with relevant "technical" issues. For example, if part of the course is Internet-based, several questions must be answered. What platform will be used WebCT, Blackboard, or something else? Which institution will host the site? Who will design the web site? Who will upload photographs and other materials that might be used? And, if part of the course utilizes video conferencing, several additional questions need to be addressed. Does each institution have an adequate video conferencing facility? What type of connection can the institutions make (e.g., ISDN, IP, etc.)? Can the institutions work around large time differences in the two locations? Who will pay for ISDN connections, which are expensive?

\section{First Global Classroom: University of Pretoria and University of Memphis}

The global classroom course occurred primarily in September and October of 2003. For two weeks, students focused on various theoretical issues related to the effects of information technology on development. For four weeks, students examined whether "place" (that is, local history and culture) still matters in an increasingly global society. And for two weeks, students studied ways to increase information technology around the world, especially in countries that lack adequate resources.

A major part of the course not only studied information technology, but also used information technology to connect the students across nearly 8,500 miles. Throughout the course, two different asynchronous discussion rooms were available. One was an "open chat room," where students could talk about virtually any topic. Most of the discussion revolved around non-course material, such as popular music in South Africa and the United States, sports, leisure activities, types of parties that the students attend, and so on. The other discussion room focused on the video conferences that were a vital part of the course (see below). Prior to the video conferences, one or more of the instructors posted a set of questions or a short lecture that outlined the main issues associated with the conference. And, following the video conference, the students continued their discussion on-line. There discussions frequently were more intense than the actual video conferences, and they lasted for several days - and sometimes longer!

An interesting example of inequality of access to information technology emerged early in the course. Specifically, the Memphis students sent frequent messages to their Pretoria colleagues, and it was often several days before they received a response from most of them. This frustrated the Memphis students, who initially interpreted this as a sign of apathy on behalf of the Pretoria students. But the interpretation was incorrect as they would learn. During one video conference, the instructors asked this question: "How many of you have a computer at home that is connected to the Internet?" More than $70 \%$ of Memphis students' hands went up. Fewer than $20 \%$ of Pretoria students' hands were raised. To communicate with their Memphis counterparts, Pretoria students had two options: go to an Internet Café and pay for a connection (not feasible for many students on a tight budget) or send messages from a campus computer lab during class time. Recognizing the challenge, Prof. Britz and Mr. Bester gave students an opportunity to respond during his regular class time. The computer labs were oversubscribed and therefore students were seldom able to use the labs outside of class time. (In 2007, the instructors conducted a similar poll, and nearly $80 \%$ of hands in both classes went up.)

Although students enjoyed communicating via the Internet, it paled in comparison to the popularity of the live interactive video conferences. Four times 
during the course (spaced about every two weeks), the students would talk to each other for 75+ minutes on a wide range of topics associated with the course. (At that time, the connections were made via an ISDN connection that cost about $\$ 500$ per conference [the University of Pretoria and the University of Memphis split the costs]). The instructors would determine the primary topic well before the video conference, and they would post a question or two on the discussion board prior to its start. Each video conference also began with a short "lecture" (10 minutes) from one of the faculty members. The first video conference addressed the theoretical issue, "Are you a 'cyber-optimist' or a 'cyber-pessimist' (i.e., is information technology good for the world, or not?)? The second video conference examined the role of "place" in global perspective. The third looked at the effects of information technology on health, education, and overall quality of life. And the fourth focused on possible solutions to the global digital divide.

Prior to the video conference, it is very important for instructors on both sides to have their students thoroughly prepared for the day's theme. Students need an understanding of the content as well as the technology being utilized. For example, we talked about the different technologies that can connect video conference partners (e.g., ISDN, IP, etc.), along with the pros and cons of each approach. If students are not prepared for the technology, they may be frozen by the "Wow factor" that video conferencing usually brings to first-time users who are surprised with the "real time" reality of the experience.

Following the short lecture that started each conference, the faculty member normally would ask an initial question (or questions), to which each side would respond. The faculty member on the other side would then have the opportunity to respond and ask a question (or questions), to which each side would again respond. Once the discussions begin, it is essential to have good leaders on both sides. The leaders must work together to give both sides an equal opportunity to speak and they must take advantage of impromptu topics that enrich the discussion. They must also allow students to ask each other questions, which can lead to very interesting discussions.

A particularly valuable and moving segment occurred during the final 20-25 minutes of the last video conference. All of the students were given an opportunity to express their sentiments about what the video conferences meant to them. Students on both sides said that the conferences had opened their eyes, reduced stereotypes (such as, "Americans are all rich and arrogant" and "South Africans are unsophisticated and live in the bush"), enhanced intercultural understanding, and made them much more interested in visiting the others' country. Moreover, and importantly, the course "forced" each side to look more intensively at its own challenges. For instance, upon learning more about apartheid and race relations in South Africa, the Memphis students observed (primarily during private class sessions) that Memphis still suffers from some of the same challenges. Racial tension is very real in Memphis, a reality associated with history, poverty, and violence. One Memphis student commented, "We still have our own apartheid right here." Other students disagreed with this perspective - the point being that the video conferences prompted an excellent discussion of race relations in the "other place."

In addition to video conferences and Internet discussions, the students used one other form of information technology to work together. Specifically, for their final assignment, they completed a photo essay that required good digital photographs. The classes were divided into five "global teams," each of which had students from the University of Pretoria and University of Memphis. Each team decided what topic it wanted to investigate (a task accomplished through intense email negotiations!) and then Pretoria students took relevant photographs in the Pretoria region and Memphis students took relevant photographs in Tennessee. The photographs were exchanged over the Internet and each individual student was required to write her/his own essay from the topics. Topics included "The fight against HIV/AIDS," "Providing healthcare to poor communities," "The role of religion in society," "International cuisine as an expression of culture," and "Popular culture and society."

In conclusion, students were assigned a grade (or mark) for each section of the global course (Internet discussions, video conference participation, and photo essay). The Memphis students were graded only by their instructor (Prof. Bradshaw or Prof. Rushing) and the Pretoria students were graded only by their instructor (Prof. Britz and Mr. Bester). Although instructors from both sides shared comments about the overall performance of students, there was never a desire for one side to grade the other's students. 


\section{Broadening the Scope: Subsequent Global Classrooms}

Following the success of the initial global classroom, the project has been repeated and expanded in three ways.

First, the global classroom concept has continued at the University of Pretoria and the University of South Carolina Upstate (USC Upstate). Coetzee Bester assumed primary responsibility for the course at the University of Pretoria (after Prof. Britz moved to the University of Wisconsin Milwaukee) and Prof. Bradshaw assumed primary responsibility for the course at USC Upstate (when he moved there). The two universities had a global classroom in September - October 2005 and again in September October 2006. Although the topics and themes have changed slightly since the initial course in 2003, the overall organization and format have remained the same. Moreover, the same information technologies (Internet discussions, video conferences, and digital photography) have been utilized in all three courses.

Interestingly, the global digital divide made the video conferences more challenging over time. As mentioned earlier, ISDN connections were used during the initial global classroom project in 2003. Both sides utilized this technology. In recent years, however, most U.S. universities (including USC Upstate) have moved away from ISDN technology because it usually is not needed - instead, IP connections are the norm and they are essentially free! Unfortunately, however, IP connections are problematic when, as in the case of the University of Pretoria, there is insufficient broadband capability to utilize this technology. Thus, the only way that the University of Pretoria and USC Upstate can interact in a reliable way is for the former to utilize an ISDN connection to a "bridge," which can convert the transmission and make possible an IP connection with USC Upstate. The University of Pretoria normally used a bridge in the Netherlands, and the typical cost was about $\$ 385$ for a 90 -minute video conference. In other words, lack of broadband capability was financially costly to the University of Pretoria.

Second, and very exciting, the global classroom has moved successfully to the high school level. During a several month period in 2006, USC Upstate worked closely with both the Pretoria High School for Girls and Spartanburg High School to initiate a very successful project that has run much of the 2006-2007 academic year. Since October 2006, the two schools have engaged in three video conferences and exchanged more than a dozen photoessays on a wide variety of topics. The three topics investigated thus far are: "Is information technology a positive force in the world?"; "Is popular culture uniting the world?"; and "War: when (if ever) is it justified?" The students have also exchanged 451 emails (as of May 10, 2007) over a dedicated discussion board on WebCT .

By all accounts, the global classroom for high school students has been enormously successful. The students have taken the project very seriously and participated at an impressive level. The successful interaction has also resulted in (1) an invitation to the headmistress of the Pretoria High School for Girls to participate in an international conference in Spartanburg, South Carolina (March, 2007), and (2) an invitation for two students and a teacher from the Pretoria High School for Girls to attend a Youth Leadership Institute on the USC Upstate campus (June, 2007). Moreover, an exchange program from USC Upstate will visit the Pretoria High School for Girls in June, 2007.

It is important to point out that global classrooms at the high school level face special challenges, most of which ultimately relate to issues of equality and ethics. We mention a few here:

- High schools normally do not have video conferencing facilities or software packages like WebCT. Thus, they must partner with institutions that do - or pay substantial rental fees. In the case of our high school global classroom, the Pretoria students used the video conferencing facilities at the University of Pretoria and the Spartanburg students used the facilities at USC Upstate. A grant awarded to USC Upstate from the U.S. Department of Housing and Urban Development covered the costs associated with the video conference (approximately $\$ 385$ for a 90-minute video conference). Moreover, USC Upstate hosted the WebCT site for the global classroom, and students at both high schools were given passwords to the site (no charge to anyone).

- High schools also need partners who bring expertise on technology and curriculum issues. In this case, the two high schools had extensive assistance from both USC Upstate and the University of Pretoria on such issues. Prof. Bradshaw coordinated the effort at USC Upstate and Prof. Theo Bothma provided crucial support at the University of 
Pretoria. All of the lessons learned in the University-level global classrooms were applied to the high school classrooms.

- Although external support is important, nothing is more important than committed teachers and administrators within the high schools. Just as with global classrooms at the university level, both sides must have at least one "champion" who will advocate for the project at all times. They need to be outstanding teachers who have the support of their respective administrators and who can work well with people at different institutions. Ms. Janis Haynes (social studies teacher at Spartanburg High School) and Ms. Jeanne Cyrus (English teacher and debate coach at the Pretoria High School for Girls) were true champions for the global classroom - and kept it going at all times. And they had strong support from the principals at each institution.

In the end, global classrooms need huma n, capital, and technological resources to succeed. Poor schools will have difficulty achieving access to such resources.

Third, in addition to formal classrooms, the global classroom concept can be used for occasional conferences. For example, we used video conferencing during an October 2005 international conference on the USC Upstate campus titled, "Using Information Technology to Globalize the Curriculum." During one session at the conference, a panel of South African experts (led by Mr. Coetzee Bester) talked via interactive video with conference participants about a number of social, political, and economic factors influencing South Africa. The panel broadcast from the video conferencing facilities at the University of Pretoria. And during June 2007, 50 high school students at a Summer Youth Leadership Institute to be held on the USC Upstate campus will hold a video conference with youth leaders in South Africa. Again, the University of Pretoria and USC Upstate will provide their facilities for the conference.

\section{Conclusion and Recommendations}

This paper has discussed, based on case studies, the use of global classrooms at the university and high school levels. In our view, the success of these international initiatives is due to two common char- acteristics: they (1) rely on committed and welltrained professionals who know how to create and sustain such projects, and (2) possess the financial and technological resources to make the projects possible. Unfortunately, there are relatively few institutions across Africa and the rest of the developing world that have the resource capacity to launch similar global classroom initiatives. The impediments to widespread use of these classrooms are related to issues of inequality. On the positive side, however, this also means that global classroom initiatives could be much more prevalent if several key issues are overcome. We recommend three here.

First, teachers in the developing world (and, for that matter, the economically developed world) need intensive training in how to incorporate information and communications technology into the classroom. Although the acquisition of new computers, new servers, and new satellite hook-ups would be a positive step, they are not particularly useful without trained teachers who can use them in an effective and creative manner. It is not just a matter of understanding the technical use of the equipment; instead, it is devising a curriculum that incorporates the new technology in a creative learning environment.

Training programs for teachers need to include several components:

- Teachers need intensive training (several weeks) at institutions that have innovative programs in the area of teaching with technology. It would be an invaluable opportunity for teachers to see the programs in action, receive instruction in relevant pedagogical and technical issues, talk to students and instructors, and build networks that will serve them well into the future. These training opportunities can take place anywhere in the world that has the requisite facilities and programs.

- "On-site" training is also important. Visits by teachers and technology experts to schools with new technology would also be valuable. It would enable teams of educators from the local school and outside the local school to work together on a variety of issues.

- On-line resources are also a crucial part of (continuous) training for educators throughout the world. Good on-line resources can be used for "basic" training in technology and curriculum issues, and they can be used 
for a wide variety of "advanced" discussions on an on-going basis. Sophisticated discussion boards on "teaching with technology," "incorporating indigenous knowledge in a digital age," and a myriad of other topics would be an outstanding resource for teachers in all regions of the world.

Second, institutions in the developing world need access to computers, servers,

video conferencing equipment, and other electronic resources. And, if they acquire these resources, they need assistance maintaining them. The value of many equipment donations has eroded over time because there is no provision for maintaining and repairing equipment. Moreover, as already mentioned, lack of broadband access remains a difficult problem that slows connectivity and increases the cost of doing business. Greater resources, combined with well-trained "human capital," would go along way toward resolving some of Africa's most intractable IT challenges.

It would be enormously beneficial if international and regional actors would provide the human, financial, and technological resources to help local actors develop creative solutions to the digital divide. In Africa, for example, the New Partnership for African Development (NEPAD) has launched a very exciting "e-schools" initiative designed to connect 600,000 schools across the continent through information technology. NEPAD has already supplied many schools with computers, satellite hook-ups, television monitors, and video conferencing equipment. The challenge ahead is to (1) provide the necessary resources to maintain the equipment and train technicians to repair it, and (2) train teachers how to use the equipment and, perhaps most important, to integrate technology in the classroom in an effective manner.

Third, partnerships are essential in building global classrooms. Partnerships expand human, capital, and technological resources. In our case, the relationships among the universities and high schools (and the key players at each institution) made possible a unique global learning experience. It is also important to point out that some partnerships along the way did not work out! This project attempted to recruit several other institutions and, for various reasons, they opted not to be a part of the initiative. Several expressed great interest initially but then, when hard work and resources were required, they dropped out. This again underscores our primary argument: global classrooms are extremely valuable and they require great commitment on the part of all partners.

Global inequality has maintained a serious digital divide that places developing countries at a distinct disadvantage. Addressing this inequality is a matter of ethics and social justice precisely because information poverty maintains other types of poverty. We hope that our initiatives will play a small role in reducing poverty.

\section{Biblography}

Bradshaw, York, Kathleen Fallon, and Jocelyn Viterna. 2005. "Wiring the World: Access to Information Technology and Development in Poor Countries." Research in Social Stratification and Mobility 23: 375-397

Britz, J. J. 2004. To know or not to know: a moral reflection on information poverty. Journal of Information Science, 30(1), 192-204.

Britz, J.J. 2007. A Critical Analysis of Information Poverty from a Social Justice Perspective. Ph.D. Thesis, Department of Information Science, University of Pretoria.

Britz, J. J. \& Blignaut, J. N. 2001. Information poverty and social justice, South African Journal of Library and Information, 67(2): 63-9.

Britz J. J. \& Lor, P. J. 2003. A moral reflection on the flow from south to north with specific reference to the African continent. Libri, 53(3): 160-173.

Britz, J.J., Lor, P.J. \& Bothma, T.J.D. 2006. Global capitalism and the fair distribution of information in the marketplace - a moral reflection from the perspective of the developing world Journal of Information Ethics (In press).

Capurro, R. 2000. Ethical challenges of the information society in the $21^{\text {st }}$ century. International Information and Library Review, 32(3\&4): 257 276.

Castells, M. 1998. End of millennium. In: The information age: economy, society and culture, vol. III. Malden: Blackwell.

Internet World 2007. www. internetworldstate.com/stats/htm. Accessed May 10, 2007.

Norris, Pippa. 2001. Digital Divide: Civic Engagement, Information Poverty, and the Internet Worldwide. Cambridge: Harvard University Press.

Sassen, Saskia. $3^{\text {rd }}$ ed. 2006. Cities in a World Economy. Boston and London: Pine Forge Press. 